\title{
Porphyria cutanea tarda
}

— Ein 51-jähriger Mann mit langjährigem schädlichen Alkoholkonsum, einer chronischen Hepatitis $\mathrm{C}$ und Leberzirrhose suchte wegen eines vermehrten periorbitalen Haarwachstums seinen Arzt auf. Im Bereich der lichtexponierten Hautareale fanden sich in Abheilung befindliche, z. T. mit Schorf bedeckte Hautläsionen und Narben.

Der Mann schilderte eine gelegentlich auftretende schmerzhafte Blasenbildung im Bereich des Nackens, der Unterarme und der Handrücken (Abb. A). Der Urin des Patienten fluoreszierte im Wood-Licht rosafarben, was für Anwesenheit von Uroporphyrinen sprach (Abb. B: Urin des Patienten [mit Stern]; normaler Urin zum Vergleich im weißen Licht). Abb. C zeigt die beiden Urinproben im Ultraviolettlicht. Nachdem sich im Urin des Mannes eine erhöhte Konzentration von Uroporphyrin nachweisen ließ, wurde die Diagnose einer Porphyria cutanea tarda gestellt.

\section{Kommentar}

Die Erkrankung beruht auf einer verminderten Aktivität der Uroporphyrin-Decarboxylase. Die sporadische Form ist häufig mit einer chronischen HCV-Infektion oder einen alkoholischen Leberparenchymschaden assoziiert. Das Phänomen einer Hypertrichose im Gesichtsbereich kommt bei dieser Erkrankung so häufig vor, dass es als fast pathognomonischer Hinweis für das Vorliegen einer Porphyrie gewertet werden kann. Unter einer Therapie mit niedrig dosiertem Chloroquin, Lichtschutz der Haut und Verringerung des Alkoholkonsums konnten die Hautläsionen innerhalb von sechs Wochen zur Abheilung gebracht werden.

H. S. FÜESSL -

- Chih-Chieh Chan und Sung-Jan Lin

(National Taiwan University Hospital Taipei, Taiwan 009015@ntuh.gov.tw): Porphyria cutanea tarda. New Engl. J. Med. 365 (2011), 12, 1128.

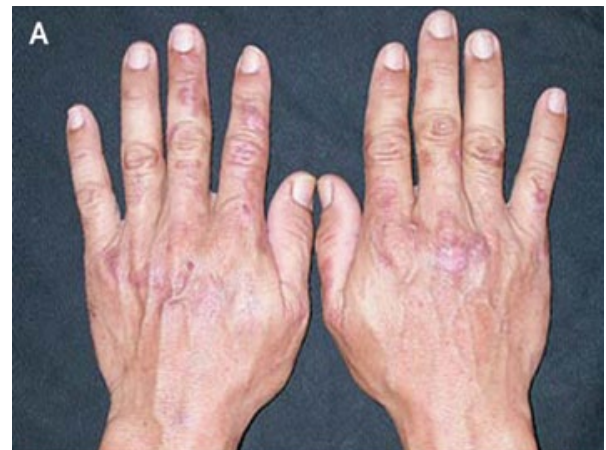

Hautläsionen

(A) und Urin im Normal- (B) und UV-Licht (C). Stern: Patientenurin, $\mathrm{N}$ : normaler Urin zum Vergleich.



